\section{Aivision of Analytical Science
Identification of Sulfur Mustard Hydrolysis Products
by LC-UV-SPE NMR}

\section{Urs C. Meier*}

Correspondence: Dr. U. Meier, Swiss NBC Defence Establishment, Spiez Laboratory, CH-3700 Spiez, Tel.: +413322816 92,

E-Mail: urs.meier@babs.admin.ch

Keywords: Environmental sample · LC-UV-SPE NMR · Solid phase extraction $\cdot$ Sulfur mustard

Sulfur mustards (SM) are strong vesicants which form blisters on the skin and in the lung. Full body protection is required as countermeasure against SM. SM were first used during World War I (WWI) in 1917 near Ypres by the German military. Since WWI SM or other chemical warfare agents (CWA), notably organophosphorus nerve agents like Sarin, have been used on a large scale repeatedly, most recently in the civil war in Syria. The remaining CWA stockpiles are mostly made of organophosphorus nerve agents and SM.

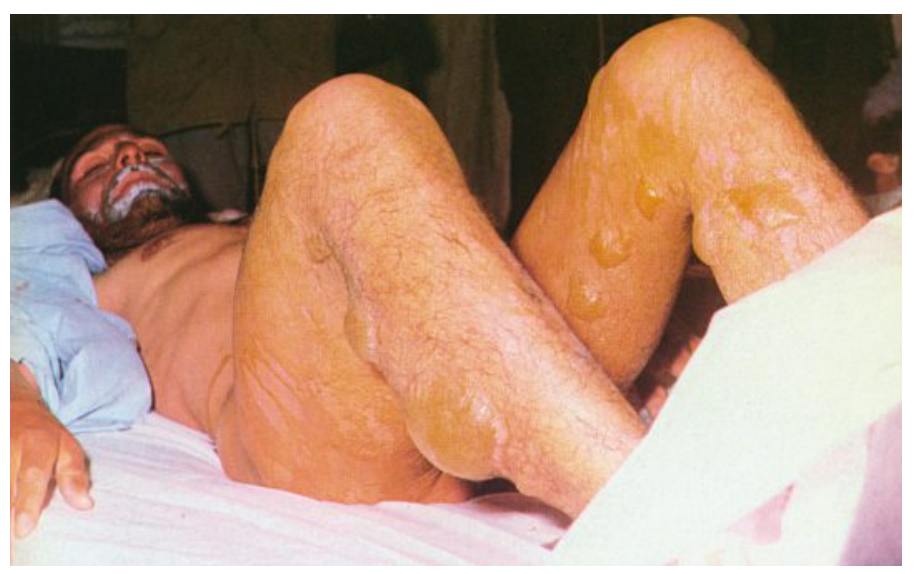

Iranian victim of exposure to sulfur mustard. 'A short documentation on the Iraqi army's use of chemical weapons', published by the Embassy of the Islamic Republic of Iran, Stockholm, Cultural Section, April 1984.

Analytical methods for the detection and unambiguous identification of CWA are needed for the verification of the chemical weapons convention, for the protection of the population, and for the medical treatment of victims. However, the analysis in case of an alleged use of chemical weapons cannot be restricted to the CWA themselves as the CWA undergo degradation in the environment. As an example, SM can be hydrolyzed. These degradation/hydrolysis products must be included in the scope of analysis.

${ }^{1} \mathrm{H}$ NMR is a powerful spectroscopic method for the identification of chemicals. The application of ${ }^{1} \mathrm{H}$ NMR to the analysis of environmental samples is in most cases not limited by its sensitivity but by the signals from the background chemicals present in the sample which partially or completely obscure the analyte signals. This necessitates a sample preparation step to isolate the analytes from the background chemicals. In the

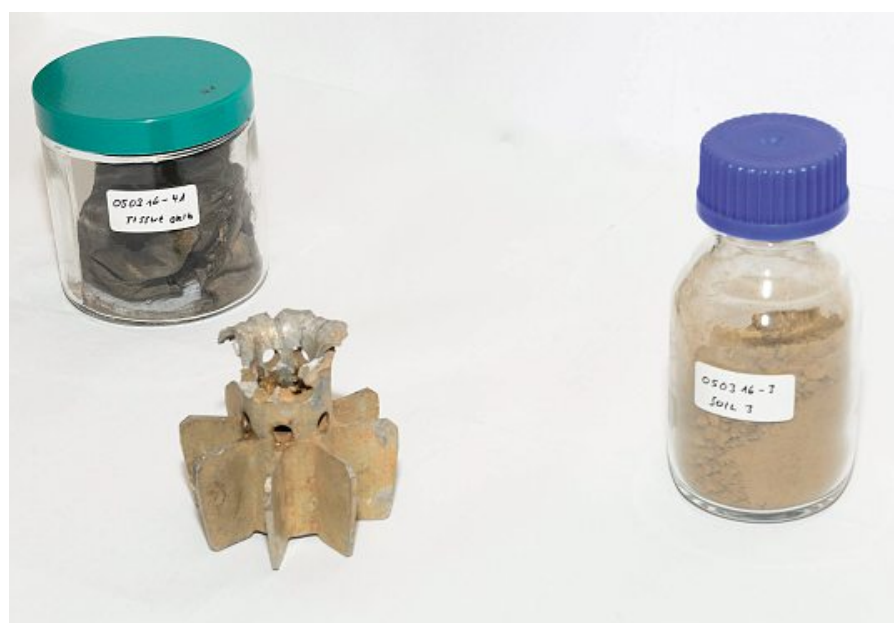

Samples suspected of contamination with sulfur mustard.

liquid chromatography-UV detection-solid phase extractionNMR technique, the SM hydrolysis products are separated from the background chemicals by LC, detected by UV, trapped and concentrated on a SPE cartridge and after elution in an NMR tube identified by ${ }^{1} \mathrm{H}$ NMR. Detection limits of 200-450 ng of analyte injected on the column are obtained for ${ }^{1} \mathrm{H}$ NMR spectra recorded at $500 \mathrm{MHz}$ using a cryoprobe and an acquisition time of $15 \mathrm{~min}$. LC-UV-SPE NMR is a powerful method to identify SM hydrolysis products in environmental samples.

Reference

Received: February 4, 2014

Urs C. Meier, J. Chromatogr. A 2013, 1286, 159.

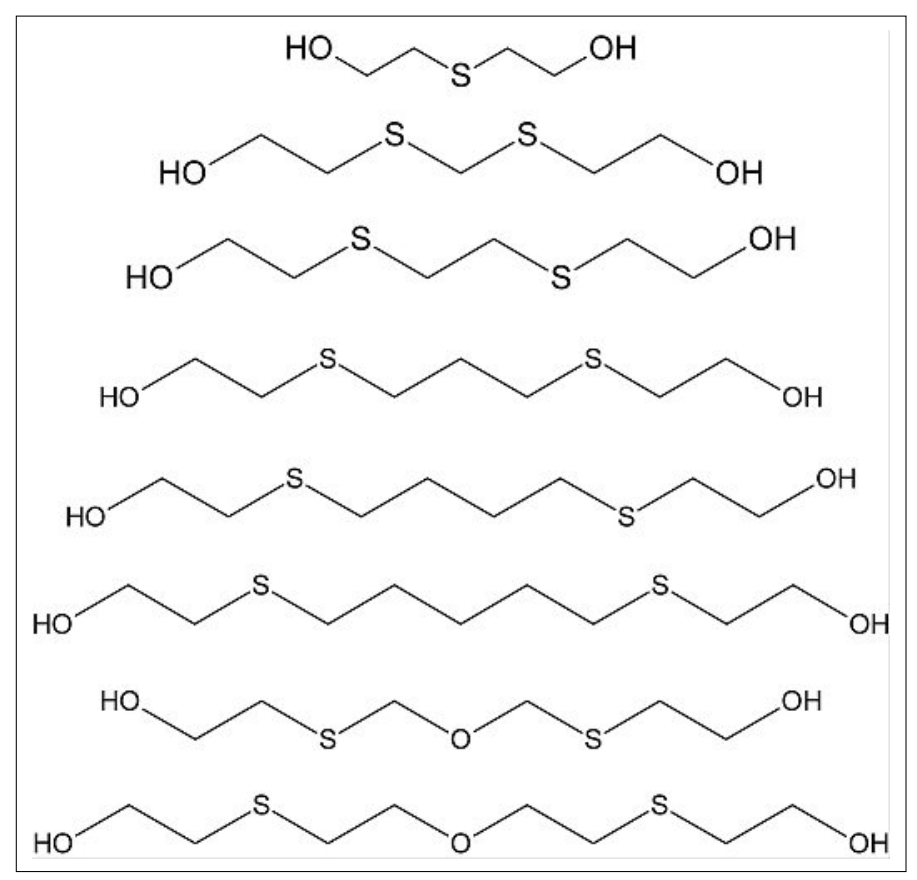

Sulfur mustard hydrolysis products. 